\title{
LEMBRE DE MIM: CONSIDERAÇÕES SOBRE A NATUREZA JURÍDICA DA DIGNIDADE POST MORTEM E O FILME "VIVA! A VIDA É UMA FESTA"
}

\author{
Marco Antonio Turatti Junior ${ }^{1}$
}

\section{RESUMO}

Com o diálogo subjetivo que o direito e arte se permitem, se confronta a partir do filme "Viva! A vida é uma festa" (2017), a busca de uma natureza jurídica da dignidade post mortem. Assim, passando por várias reflexões e institutos jurídicos brevemente explanados neste trabalho, como direitos da personalidade, dignidade da pessoa humana, princípio da afetividade, se conclui que o direito é um sistema desenvolvido para as pessoas vivas. E assim, uma tutela jurídica da dignidade post mortem depende da compreensão dos entes vivos que a dignidade após a morte é uma unidade do instituto que possuía em vida.

PALAVRAS-CHAVE: dignidade da pessoa humana; direitos da personalidade; memória; princípio da afetividade; direito de família.

\section{REMEMBER ME: CONSIDERATIONS ON THE LEGAL NATURE OF POST MORTEM DIGNITY AND THE MOVIE “COCO”}

\begin{abstract}
With the subjective dialogue that law and art allow themselves, this work confronts from the movie "Coco "(2017), the pursuit of a legal nature of postmortem dignity. Thus, passing through several reflections and legal institutes briefly explained in this work, such as rights of personality, dignity of the human person, principle of affectivity, it is concluded that law is a system developed for living people. And like the legal guardianship of postmortem dignity depends on the understanding of living beings that dignity after death is a unit of the institute that it possessed in life.
\end{abstract}

Key-words: dignity of the human person; personality rights; memory; affectivity principle; family right.

\section{INTRODUÇÃO}

"Lembre de mim, / não sei quando vou voltar/Lembre de mim, /Se um violão você escutarl/ Ele com seu triste canto/ te acompanharál e até que eu possa te abraçar, /lembre de mim." .2.

\footnotetext{
${ }^{1}$ Mestre em Ciência Jurídica pelo Programa de Pós Graduação em Ciência Jurídica da Universidade Estadual do Norte do Paraná. Especialista em Justiça Constitucional e Tutela Jurisdicional dos Direitos pelo curso de Alta Formação da Universidade de Pisa, na Itália, em 2013. Graduado pela Universidade Estadual do Norte do Paraná em 2015. Advogado e professor. E-mail: juniorturatti@hotmail.com.

2 Trecho da música "Lembre de mim" (original "Remember me", composição de Robert Lopez e Kristen Anderson-Lopez, versão brasileira do filme "Viva! A Vida é uma Festa" (Coco, Disney/Pixar, 2017). Em 2018, a música foi premiada com o Oscar de Melhor Canção Original.
} 
Alguns assuntos no ensino jurídico passam desapercebidos ou dotados apenas de uma tecnicidade comum a área que não possibilita seus estudiosos a pensarem ou questionarem. Assim, é a ideia da morte no ordenamento civil. Muito antes de qualquer discussão sobre a natureza jurídica da dignidade após a morte, o conceito de morte é sempre imbuído de outras questões - ditas mais relevantes ao direito - como a sucessão, transmissão de direitos ou herança. Questões como essa temática são mais vistas subjetiva ou culturalmente importantes, e acabam por não figurar discussões mais acaloradas sobre o assunto.

Não que o tema "morte" não seja ensinada pela prática civil ou não tenha espaço no ensino jurídico atual, longe disso, ele está lá, mas as discussões mais abstratas não são possíveis se não existir um espaço apropriado como esse da intersecção de valores como do direito e arte. Para além dos efeitos jurídicos que a morte implica no ordenamento jurídico, a proposta deste artigo é tratar sobre ela mesma, culturalmente falando e sua influência na sociedade.

Desta forma, quando se compreende a morte como um ritual de passagem ou o fim da personalidade jurídica, a dignidade da pessoa para após esse período é um imbróglio na seara do direito, pois muitos doutrinadores irão conceitua-la ou compreende-la de formas variadas. O que o trabalho se propõe é discutir, sem entrar na questão religiosa ou da tradição do "retorno dos mortos" num Dia de los muertos mexicano como no filme, é a dignidade da pessoa após a morte, se ela compreende a continuação de um direito da personalidade, ou se depende da atuação da família, então compreende a uma faculdade exclusiva de quem está vivo, e demonstrando as críticas e as possibilidades que o tema pode ocasionar num debate mais interdisciplinar do direito.

Assim, o trabalho se utiliza do método dedutivo, trazendo e analisando a partir de uma obra cinematográfica - Viva! A vida é uma festa - os vários contextos da morte no direito civil. O presente artigo trabalha seus conceitos enquadrando a sua natureza jurídica não em características inovadores, mas permeando e possibilitando a discussão em temáticas mais abrangentes e abrindo ao diálogo interdisciplinar, tentando contribuir à discussão da existência e cultura humana, o valor da morte no cenário jurídico.

\section{O filme Viva! A vida é uma festa e a questão cultural sobre a morte}


O filme "Viva! A vida é uma festa" é um filme de animação da Disney/Pixar, do ano de 2017, que apesar do nome, coloca em pauta os reflexos da morte no cenário familiar. Apesar de ser um filme comercialmente falando com o alvo infantil, o debate que ele se propõe produz grandes discussões para todas as idades, bem como para o ordenamento jurídico. O direito é feito e regulado para as pessoas vivas, com poucas determinações de regulação com eficácia post mortem (além das consequenciais deste caso, como o direito sucessório), mas os sujeitos envolvidos são as pessoas vivas. Assim, com o auxílio de obras de arte de fantasia, este artigo consegue promover uma discussão para além vida, sem dogmas ou ideologias filosóficas e/ou religiosas, mas sim, apenas com o intuito jurídico.

No filme, pela cultura mexicana do Dia dos Mortos, os mortos conseguem voltar ao convívio familiar, mesmo que invisíveis, se a família deixou a oferenda de acordo com a tradição. E no filme se repara que mesmo mortos, os indivíduos ainda dependem de relações dos entes familiares vivos, e sofrem os reflexos de suas ações antes de morrer. No mundo “dos mortos", percebe-se uma constante manutenção da dignidade e de valores próximos da vida humana, como o afeto e a personalidade.

Dentre tantos personagens, além do protagonista que na luta pelo sonho de cantar e se dedicar pela música une os dois mundos, pode-se destacar dois interessantes e multifacetados personagens: Ernesto de la Cruz e Hector. O primeiro é um cantor famoso, com fama mundial entre os vivos e os mortos, e vive da fama que conquistou. O seu legado cultural é ainda mantido com a relação de seu nome e mantém o que se pode traduzir para os instrumentos jurídicos, como o direito à honra, à imagem e a sua própria personalidade. $\mathrm{O}$ segundo personagem começa como um malandro que tenta enganar o sistema de visitas dos mortos ao mundo vivo, mas ao longo do filme começa-se a perceber sua integridade e a enganação que ele sofreu em vida. Ao final, é preservada a sua integridade física e psíquica, além do direito autoral de suas músicas roubadas pelo cantor famoso.

O que liga essas duas histórias com a moral do filme é o sentimento que une os sonhos e a integridade da personalidade do protagonista e de Hector, que por fim acaba se revelando o tataravô do herói. A família e o sentimento de pertencimento que ela dá para ambos é o que mantém a tradição e toda a mitologia do filme indicando que o reconhecimento familiar da pessoa e dos próprios sonhos fazem a diferença. Por isso, que na história do filme é mostrado que as pessoas esquecidas pelas pessoas vivas, também não há espaço no mundo dos mortos, e acabam tendo sua morte fatal e final. 
Assim, o artigo demonstra também reconhecer no direito o instituto e a eficácia post mortem de uma dignidade para além vida. O direito surge e existe para as pessoas vivas, e mesmo com alguns autores divergindo ou algumas críticas às exceções do código civil, o direito se regula para e entre os vivos, e qualquer modalidade de proteção de quem não possui mais essa condição de agir depende de quem está vivo, e tem essa preocupação para fazê-la. E é isso que o artigo pretende demonstrar sem questionar qualquer tradição ou cultura, ajuizando valores ao que se compreende da morte e da vida após a morte, mas como o direito se interessa por aqueles que já não possuem independência de realizar por si só seus direitos que lhes são facultados.

\section{O cenário jurídico de proteção da dignidade post-mortem: institutos e reflexões}

“A dignidade é essencial, em primeiro lugar para o reconhecimento da fundamentalidade de direitos que não estejam inseridos no catálogo constitucional de direitos e garantias fundamentais" (SARMENTO, 2016, p. 84). Tão importante quanto é reconhecer o caráter multifacetado do conceito (BARROSO, 2013, p.63) e não restringir a sua qualificação apenas ao campo jurídico. É importante e cada vez mais o direito está se abrindo para esse diálogo multidisciplinar com a arte para entender conceitos e necessidades humanas que ele precisa positivar sobre, mas de uma forma não tanto paradigmática ou cartesiana

A construção da dignidade da pessoa humana no ordenamento jurídico brasileiro se mostra necessária quando se encara o conjunto de leis como um instrumento de efetivação e prática. Não haveria como ser diferente, portanto, e um norte à pessoa humana é preciso ser dado para o ordenamento, para que se possa proteger e promover as relações sociais e da coletividade. Diante disso, as próprias formações legais - tanto positiva como negativa agem diante dessa conjectura e demonstram a multiplicidade de aparições possíveis da dignidade como uma forma de fundamentar as regras (SARLET, 2012, p. 70).

Essa análise possui muitas características relacionadas à lógica kantiana ${ }^{3}$, já que o homem não pode ser um instrumento de outras pessoas para alguma vontade, mas de suas próprias noções e compreensão de si mesmo ${ }^{4}$ (SARLET, 2007, p. 382). Assim, é justo dizer

\footnotetext{
${ }^{3}$ No reino dos fins tudo tem ou um preço ou uma dignidade. Quando uma coisa tem um preço, pode-se pôr em vez dela qualquer outra como equivalente; mas quando uma coisa está acima de todo preço, e, portanto, não permite equivalente, então tem ela dignidade (KANT, 1986, p. 77).

${ }^{4}$ Cf. KANT, Immanuel. Fundamentação da metafísica dos costumes. Lisboa: 70, 1986.
} 
que essa noção sobre dignidade da pessoa humana não é lugar-comum sobre as questões acerca dos direitos do homem, e nem poderia ser $^{5}$. A devir-dignidade baseada em vários outros aspectos e até mesmo numa responsabilidade muito maior, com viés multidisciplinar de conceitos e reflexos da sua carga valorativa, demonstram que as noções social, coletiva, psicológica, intrínseca e interna - atual e por toda a história -compreendem a sua identificação dentro do instituto ${ }^{6}$.

É a ideia, portanto, da busca da "superação de qualquer visão unilateral e reducionista e a promoção e proteção da dignidade de todas as pessoas em todos os lugares" (SARLET, 2007, p. 385). O presente trabalho ao trazer a dignidade post-mortem no título abre essa gama de opções sobre o que de fato poderá ser tutela após a morte e existência da pessoa, mesmo que a sua subsistência seja o pilar básico condicionante do termo.

A ideia da dignidade resulta de uma análise crítica e essencial para a noção de perpetuar direitos e fazê-los com que aconteça. Tanto é que muitos defendem ${ }^{7}$ a estrita relação da dignidade da pessoa humana com os direitos fundamentais positivados constitucionalmente. De total importância ao ordenamento e as formas de hermenêutica, "vêse que a dignidade é atributo intrínseco, da essência, da pessoa humana, único ser que compreende um valor interno, superior a qualquer preço, que não admite substituição equivalente. Assim a dignidade entranha e se confunde com a própria natureza do ser humano" (SILVA, 1998, p. 91). Assim, reconhece-se com essa leitura que a dignidade perpassa diversos direitos e por esses também indicam o caminho das garantias e necessidades

\footnotetext{
5 “ “...] o conceito de dignidade da pessoa humana obriga a uma densificação valorativa que tenha em conta o seu amplo sentido normativo-constitucional e não uma qualquer ideia apriorística do homem, não podendo reduzirse o sentido da dignidade humana à defesa dos direitos pessoais tradicionais, esquecendo-a nos casos de direitos sociais, ou invocá-la para construir 'teoria do núcleo da personalidade' individual, ignorando-a quando se trate de direitos econômicos, sociais e culturais" . Daí decorre que a ordem econômica há de ter por fim assegurar a todos existência digna (art. 170), a ordem social visará a realização da justiça social (art. 193), a educação o desenvolvimento da pessoa e seu preparo para o exercício da cidadania (art. 205) etc., não como meros enunciados formais, mas como indicadores do conteúdo normativo eficaz da dignidade da pessoa humana" (SILVA, 1998, p. 92).

${ }^{6} \mathrm{~A}$ ideia da morte é tão próxima à sociedade, que também se constata "uma forte associação da morte com a religião, observável em diferentes culturas. São fenômenos intricados no imaginário socialmente construído e que perpassam o tecido cultural. É nesse contexto que as subjetividades individuais são construídas, ao passo que constroem o imaginário compartilhado na sociedade" (COCENTINO; VIANA, 2011, p. 593).

${ }^{7}$ Ilustrado pela ideia de Peter Haberle, diversos autores defendem que "a maioria dos direitos fundamentais individualmente considerados é marcada por uma diferenciada amplitude e intensidade no que diz com sua conexão com a dignidade humana. Os direitos fundamentais (individualmente considerados) subsequentes, assim como os objetivos estatais e as variantes das formas estatais, têm a dignidade como premissa e encontram-se a seu serviço" (HÄBERLE, 2005, p. 129).
} 
sociais ${ }^{8}$, bem como as tradições e culturas de cada um, afinal "a morte e a velhice constituem fenômenos fortemente atrelados na cultura" (COCENTINO; VIANA, 2011, p. 598).

Como princípio constitucional, portanto, garante um norte ao aplicador de direito. Não é algo estipulado, mas indica qual caminho é melhor seguir. É notar que “[...] a dignidade que dá o parâmetro para a solução do conflito de princípios; é ela a luz de todo o ordenamento. Tanto no conflito em abstrato de princípios como no caso real, concreto, é a dignidade que dirigirá o intérprete [...]" (RIZZATTO NUNES, 2002, p. 55). Assim, não há que se conceituar ou permitir alterações de conceito; a dignidade, por si só, se constrói com as mudanças da humanidade e está expressamente relacionada com as liberdades e revoluções humanas. "Jamais uma sociedade favoreceu uma autonomia e uma liberdade individuais tão amplas em seu exercício, jamais seu destino se encontrou tão estritamente ligado aos comportamentos daqueles que a compõem" (CHARLES, 2004, p.65). E pode estipular o caminho a seguir se tiver que tutelar algum direito de eficácia com o fim da vida.

A dignidade da pessoa humana se baseia em fases constitutivas que encaram o valor intrínseco da pessoa, a autonomia dela, além de se relacionar com o mínimo existencial para sua vida e o reconhecimento disso perante seus pares. Tais componentes não são isolados uns dos outros. Eles se conflitam e as suas demarcações não são nítidas, mas comunicativas e simbióticas (SARMENTO, 2016, p. 93). Contudo, um limite a essa relação do direito com a dignidade deve ser respeitado e ver se há possibilidade de concretizar o ato. Isso está relacionado, até mesmo, pelas relações subjetivas que não tem como fixar regras para todas as manifestações subjetivas possíveis (quiçá após a morte também), mas também por questões internas ressaltadas pelos elementos constitutivos que devem apresentar peculiaridades imprevisíveis. A morte é mais forte que a consciência humana em vida.

“A afirmação do caráter absoluto do princípio da dignidade embora confortável do ponto de vista retórico, conduz na prática a resultados que poucos aceitariam” (SARMENTO, 2016, p. 97). Por conseguinte, este artigo se encaixa nas ideias dos direitos relacionados ao instituto da dignidade que devam ser compreendidos pela proporcionalidade e estrita

\footnotetext{
8 "É a base em que se assentam os direitos fundamentais, como a liberdade, a igualdade, o direito à vida, os direitos da personalidade, dentre outros e é integrado pelo valor consubstanciado na autodeterminação da pessoa humana, na vontade que rege a extensão da personalidade na atuação social. O constitucionalismo atual sanciona o estatuto dos direitos fundamentais e coloca-os dentre as principais garantias dos cidadãos. Esses direitos se apresentam como valores objetivos básicos, ao mesmo tempo que marcam a proteção de situações jurídicas subjetivas. Subjetivamente, os direitos fundamentais tutelam a liberdade a autonomia e a segurança das pessoas frente aos demais membros da sociedade e frente ao próprio Estado, limitando o poder estatal aos lindes impostos pela dignidade da pessoa humana" (MADEU, 2001, p. 102).
} 
necessidade jurídica. Desta forma, compreender qual tutela jurídica poderá protegê-la é uma tarefa ainda mais custosa e carente de abstrações que o filme ajudará na perspectiva filosófica.

Agora, dedicar-se-á o trabalho para vislumbrar a ideia de uma proteção da dignidade post-mortem em alguns cenários jurídicos, a fim de compreender a sua natureza jurídica e embasar a discussão para o próximo tópico, para analisar se ao direito interessa o além vida. Primeiramente, o instituto analisado será o conceito do direito da personalidade humana por vários autores que contribuíram com a matéria na área acadêmica para tutelar a dignidade do indivíduo após a morte.

É sabido que a personalidade humana tem seu início com o nascimento com vida, e finaliza com a morte, resguardando os direitos do nascituro. Mas, pela própria regra do ordenamento há preocupações com a personalidade após a morte, e é isso que será posto em debate pela sua efetividade do dispositivo. Na visão de cada um dos autores aqui selecionados, far-se-á um aporte com a questão do tema central deste trabalho, a fim de contribuir com a reflexão proposta pelo diálogo entre o filme e o direito.

Gustavo Tepedino entende a personalidade como um "conjunto de características e atributos da pessoa humana, considerando como objeto de proteção por parte do ordenamento jurídico" (1999, p. 26). Assim, ele defende seu posicionamento com a ideia daquilo que se faz parte intimamente da característica do ser humano, e deve ser respeitada e reconhecida pelos seus pares, e ainda juridicamente disposta como tutela necessária e garantida para aqueles que a possuem.

Entre as características levantadas dos direitos de personalidade, é interessante ressaltar a do caráter absoluto (TEPEDINO, 1999, p. 32), que indica o dever de respeitar, mas aqui defende-se com a ponderação do reconhecimento social e da preponderância de outras liberdades, e a do caráter essencialista (TEPEDINO, 1999, p. 33), que se transforma perante a especialidade da vida humana. É claro perceber que os juristas sobre o tema se pautam nas características da vida para os auxiliarem na conceituação terminológica. O que de fato, remonta ao caráter de exceção o cuidado com a morte previsto no início do Código Civil.

Para ilustrar, a personalidade, como instituto jurídico, se caracteriza pelos seguintes aspectos $^{9}$ : privados, sendo assim considerados subjetivos, próprios da pessoa; e por serem da inerentes a pessoa, são considerados de caráter não patrimonial, contudo admite-se uma

\footnotetext{
${ }^{9}$ Cf. ANDRADE, Fábio Siebeneichler de. A tutela dos direitos da personalidade no direito brasileiro em perspectiva atual. Revista de Derecho Privado, n. 24, p. 81-111, 2013.
}

\footnotetext{
Rev. de Direito, Arte e Literatura | e-ISSN: 2525-9911 | Salvador | v. 4 | n. 1 | p. 19 - 39 | Jan/Jun. 2018 
estipulação do seu valor em casos judiciais. Ainda é considerada com critérios absolutos, respeitados assim pelos seus pares, e estabelece as seguintes características: intransmissibilidade, não permitindo a cessão de direitos próprios a terceiro; irrenunciabilidade, não se pode abdicar direitos dessa categoria; imprescritibilidade, não há prazo para pleitear seus direitos; vitalício, duradouro por todas as relações da pessoa, podendo atingir até mesmo o período após a morte ${ }^{10}$. Neste caso, o que se percebe que o direito da personalidade tem a sua preocupação e inerente ligação à identidade do ser humano, tal aspecto da dignidade humana se dá então numa preocupação da continuidade dos valores ainda em respeito aos que permanecem vivos.

Assim, depreende-se que o direito da personalidade, com todas as suas características próprias ao sujeito de direito e relacionadas ao seu caráter e capacidade civis, garante o entendimento do ser como tal, e ainda o respeito de seus pares, nas mais diversas facetas do instituto (honra, imagem, etc.). Deste e de outro modo, ao estender sua proteção para também além vida é uma maneira de garantir que sua lembrança seja de fato respeitada e ainda garantida como o sujeito que foi em vida. E aí, o direito posto à proteção da personalidade é exercido pela família em prol dessa lembrança, e não um direito factualmente da pessoa morta, que já teve o final legal de sua personalidade.

Francesco Carnelutti diferencia a ideia do objeto e do sujeito da relação, portanto não compreendia que a ideia das atribuições do indivíduo condizia com a personalidade dele (1955, p. 3). Assim, nas ideias do professor italiano, "a personalidade existe enquanto existir o espírito ou, pelo menos, o interesse deste a ser tutelado. A memória está diretamente relacionada com esta essência abstrata presente no corpo" (ALMEIDA NETO, 2008, p. 62). E tal como no filme, a personalidade para essa corrente perdura enquanto há memória dos seus efeitos, e assim o direito existe na sua forma a tutelar.

Pontes de Miranda endossa a posição contrária a essa corrente defendendo que a formação uma que todos os elementos constituem a personalidade. (PONTES DE MIRANDA, 2000, p. 38) A personalidade, assim como também compreende Gustavo Tepedino, é um valor a nortear as relações do ser humano com sua própria essência (TEPEDINO, 1999, p. 26), portanto seguem o caráter do ordenamento civil de início e fim com a trajetória humana, em termos médicos.

${ }^{10}$ Cf. GAGLIANO, Pablo Stolze, PAMPLONA FILHO, Rodolfo. Novo curso de direito civil: parte geral. v. 1. 15. ed. São Paulo: Saraiva, 2013, Capítulo do direitos da personalidade. 
"A memória do indivíduo morto, contemporaneamente, tem sua salvaguarda por parentes e é tutelada pelo direito de personalidade a nível jurídico. Se o indivíduo não tem esta memória, deixa de existir e passa a ser apenas um cadáver, algo que já foi alguém [...]" (ALMEIDA NETO, 2008, p.62). Portanto, nessa compreensão, o direito aqui é referente à família, e fica resguardado à faculdade afetiva impô-lo ou não, perante os demais. Pois, de fato, a capacidade jurídica do de cujus tutelar por direito próprio findou-se.

Adriano de Cupis defende a ideia do direito da personalidade com caráter e ocupação essencial para a estruturação do ordenamento jurídico. Assim, defende com esse patamar de atuação que os tais direitos essenciais na sua classificação das normas se identificam com os de personalidade, uma vez que "a denominação de direitos da personalidade seja reservada aos direitos essenciais, justifica-se através da consideração de que estes se constituem o núcleo mais profundo da personalidade" (DE CUPIS, 1982, p. 13). O que se depreende aqui é uma formação mais essencialista em vida, do sujeito atuante no cenário jurídico.

Orlando Gomes, pioneiro no Brasil a reconhecer tal tutela, ainda a defendia a larga esfera da personalidade, abordando a sua existência no ordenamento jurídico como essencial e necessária para a coletividade e os bons costumes (1966, p. 44). Ainda defende, que "é o direito da pessoa humana a ser respeitada e protegida em todas as suas manifestações imediatas dignas de tutela jurídica, assim como na sua esfera privada e íntima" (GOMES, 1983, p. 254). Não há como descortinar a preservação da memória de um ente querido dessa seara, assim reconhecer que se ela quiser proteger, ela poderá. A liberdade que legitima o pensamento, visto aqui, indica a ideia de uma defesa ampla de sua atuação em todas as vertentes que se demonstra ao direito.

Ou seja, o limite do direito da personalidade da pessoa morta acabou, mas possui o da família em defende-lo. Assim para concluir a ideia defendida por Orlando Gomes, reproduz-se:

A personalidade é um atributo jurídico. Todo homem, atualmente, tem aptidão para desempenhar na sociedade um papel jurídico, como sujeito de direito e obrigações. Sua personalidade é institucionalizada num complexo de regras declaratórias, nas condições de sua atividade jurídica e, nos limites a que se deve circunscrever (GOMES, 1999, p. 141). 
Limongi França defende que uma positivação limitadora sobre o direito da personalidade é problemática, e que as discussões sobre as expressões humanas em decorrência a personalidade devem ser levadas em consideração, em suas projeções e prolongamentos (1983, p. 9). De tal forma que "direitos da personalidade dizem as faculdades jurídicas cujo objeto são os diversos aspectos da própria pessoa do sujeito, bem assim da sua projeção essencial no mundo exterior" (FRANÇA, 1994, p. 1033). Assim, entende-se que defender a personalidade de uma pessoa morta é um desdobramento do direito tido em vida.

Capelo de Souza, traz a ideia de direito da personalidade de natureza capaz de englobar elementos sociais, psicológicos, ambientais, culturais e afetivos (1995, p. 93). Nessa toada de pensamento, o autor defende que a intimidade ou a identidade de uma pessoa é um conjunto influenciado por várias manifestações e denominações externas e históricas que se possui. Dessa forma, encontra-se uma formação mais ampla e global da ideia de personalidade, tal como foi defendida no parágrafo anterior, e retomando até mesmo a ideia do próprio filme, a lembrança da personagem está culturalmente arraigada nos seus costumes e, portanto, é dignificante à personalidade dos vivos, a proteção post-mortem.

Pedro Pais de Vasconcelos resguarda o direito da liberdade como a qualidade do sujeito de direito (VASCONCELOS, 2014, p. 25 e seg.), baseando suas ideias em juristas mundiais aqui já citados. Ele encontra a sua definição com exclusividade na ideia de unidade de resguardo jurídico de sua tutela. A personalidade é compreendida de maneira única para a formação do ser humano. "O direito subjetivo da personalidade tem unidade, e essa unidade decorre da unidade da pessoa e de sua dignidade. O titular do direito é uno e a sua dignidade também o é. Não há lugar para uma separação nem ontológica nem pragmaticamente" (VASCONCELOS, 2014, p. 64).

Paralelo a isso, pode-se compreender a ideia de que a existência humana é una, e quando se trata da eficácia post mortem, se está diante de uma inversão de papéis. Para corroborar, o homem não tem uma relação de coexistência com a morte, nas reflexões de Fernando Savater, "enquanto nós estamos, a morte não está; quando a morte chega, nós deixamos de estar" (SAVATER, 2011 p.22). Assim, diante do pensamento do jurista português o que podemos depreender é que a subjetividade única da personalidade não perpassa a morte. Mas, como essa morte pode ser intocável às questões de identidade, se a cultura da pessoa assim versar, como na retratada pelo filme que ela possui uma carga valorativa muito grande aos mortos e também aos familiares vivos. 
Entre tantas questões acerca da teoria da personalidade, e também das relações entre ter e ser, levantadas classicamente por Savigny, Illenek e Ferrara ${ }^{11}$, a decisão desse trabalho é encarar a construção da personalidade como um procedimento de humanidade e históricosocial. Mesmo que o seu fim seja legalmente a morte, para a cultura e os valores sociais de uma pessoa, as questões do além-vida podem ser necessárias resguardar. Carlos Alberto Bittar é o mais difundido na aplicação teórica e prática no Brasil sobre o tema (a fim de indicar aplicabilidade direta no ordenamento jurídico pátrio) e consegue identificar essa necessidade moral no seu terceiro tipo de classificação dos direitos da personalidade - distribuídos em direitos físicos, psíquicos e morais, que levam em consideração a virtude da pessoa e os atributos valorativos em sociedade (BITTAR, 2015, p.49). Destaca-se a decisão que segue:

CIVIL. DANOS MORAIS E MATERIAIS. DIREITO À IMAGEM E À HONRA DE PAI FALECIDO. Os direitos da personalidade, de que o direito à imagem é um deles, guardam como principal característica a sua intransmissibilidade. Nem por isso, contudo, deixa de merecer proteção a imagem e a honra de quem falece, como se fossem coisas de ninguém, porque elas permanecem perenemente lembradas nas memórias, como bens imortais que se prolongam para muito além da vida, estando até acima desta, como sentenciou Ariosto. Daí porque não se pode subtrair dos filhos o direito de defender a imagem e a honra de seu falecido pai, pois eles, em linha de normalidade, são os que mais se desvanecem com a exaltação feita à sua memória, como são os que mais se abatem e se deprimem por qualquer agressão que lhe possa trazer mácula. Ademais, a imagem de pessoa famosa projeta efeitos econômicos para além de sua morte, pelo que os seus sucessores passam a ter, por direito próprio, legitimidade para postularem indenização em juízo, seja por dano moral, seja por dano material. Primeiro recurso especial das autoras parcialmente conhecido e, nessa parte, parcialmente provido. Segundo recurso especial das autoras não conhecido. Recurso da ré conhecido pelo dissídio, mas improvido. (STJ REsp: 521697 RJ 2003/0053354-3, Relator: Ministro CESAR ASFOR ROCHA, Data de Julgamento: 16/02/2006, T4 - QUARTA TURMA, Data de Publicação: DJ 20/03/2006 p. 276RDR vol. 38 p. 332RSTJ vol. 201 p. 449) (grifo nosso).

Destarte, é possível reconhecer as diversas formas que a morte pode refletir na vida pessoal das pessoas e ainda precisar da proteção jurídica e se mostrar como uma parte da condição humana da pessoa. Assim sendo, nesse certame, entende-se que de certa maneira a proteção post-mortem da dignidade humana pode ser vista como uma manifestação do direito

\footnotetext{
${ }^{11}$ Cf. TEPEDINO, Gustavo. A tutela da personalidade no ordenamento civil-constitucional brasileiro. Temas de direito civil, v. 3, p. 25, 1999.
} 
da personalidade, e para tanto defensável juridicamente. Tanto que é prevista pelo Código Civil e não ataca o instituto jurídico na sua essência.

Evitando posicionar-se sobre uma teoria específica [entre a tutela ser exercida por um sucessor ou a própria personalidade promove efeitos patrimoniais para o após a morte], o STJ opta por uma orientação finalística: o fato de a pessoa já haver falecido não retira de seus sucessores a possibilidade de resguardar a sua imagem, concedendo-lhe o direito à indenização. Nesse contexto, verifica-se que não está inviabilizada a caracterização dos direitos da personalidade como direito subjetivo (ANDRADE, 2013, p. 95).

Portanto, se compreende na perspectiva dos direitos da personalidade, que a lei é imperativa ao dizer que a sua categoria finaliza com a morte, ressalvada os direitos com eficácia post-mortem que o próprio ordenamento civil diz. Hoje se assume a posição da proporcionalidade ou da cessão desses direitos para o familiar mais próximo (ANDRADE, 2013, p. 95-6). Mesmo compreendendo a personalidade como uma característica ampla e necessária para o direito, os juristas defendem como a essência da pessoa, e assim ela caracteriza e descreve quem cada um é. Então essa característica dos seres humanos em vida traçada e defendida pela personalidade -, permanecerá após a morte em lembrança e em memória. E se houver algum dano a elas, a família ou quem se sentir prejudicada poderá reivindicar tal direito, e não a ideia da própria personalidade, já findada.

$\mathrm{Na}$ sua crítica à tese da sobrevida dos direitos da personalidade, os autores Bruno Naves e Maria Freire de Sá explicitam:

À família não são transferidos "direitos da personalidade", mas é-lhe atribuída uma esfera de liberdade processual na defesa da não-infração de deveres que se refiram à "figura" do morto. Logo, o que se tem é tãosomente o deferimento de uma legitimidade processual na defesa dessa situação jurídica de dever, na qual o morto se insere, em face do juízo de reprovabilidade objetivada normativamente (2007, p. 122).

Neste trabalho, ainda destacar-se-á essa dignidade do ente familiar morto como um direito da família proveniente da sua relação de afeto. Por ora, o trabalho então demonstrou que como direito da personalidade, o instituto jurídico não apresenta total identificação, pelo fato da norma jurídica ser expressa quanto ao seu fim, mas encontra a barreira da harmonia 
coletiva na memória e lembrança do além vida mantida pelos familiares, dotados de personalidade.

Além dessa interpretação, também é válido dizer sobre o direito que, como instituto e ciente de seu cenário político e de modernidade, está se destacando na tutela dos direitos ao esquecimento e do direito à memória. Respeita-se o direito ao passado até mesmo como uma retomada ao que se viveu e que se compartilhou com a vida em sociedade. É tal qual um direito ao passado, mas com a necessidade de se reconhecer as interações subjetivas.

O reconhecimento do direito ao passado está, portanto, ligado intrinsecamente ao significado presente da generalização da cidadania por uma sociedade que evitou até agora fazer emergir o conflito e a criatividade como critérios para a consciência de um passado comum. Reconhecimento que aceita os riscos da diversidade, da ambiguidade das lembranças e esquecimentos, e mesmo das deformações variadas das demandas unilaterais (PAOLI, 1992, p. 28).

Desta maneira, reconhece-se o direito nas interações subjetivas com afã de conhecer a sociedade pela qual as mais diferentes relações sociais se interpassam e conectam em vida. Tal como a discussão na película animada, o personagem principal tem, além de uma relação de idolatria, uma inspiração ao personagem Ernesto de la Cruz, que já falecido, demonstra para ele a arte da música e o faz se sentir pertencente à sua vila, já que sua família realiza uma atividade que não há identificação. Enquanto a música é repreendida no seu seio familiar, ele possui a possibilidade de buscar reconhecimento com as fantasias de sua memória.

No conjunto da obra de Axel Honneth, é claro perceber a importância dada à liberdade. Contudo, em suma e a par de primeiras conclusões, defende-se que tal ideia não é um recurso linguístico ou do discurso, e que o reconhecimento de ambos os sujeitos deve ser calcado em uma comunicação intersubjetiva (CATTONI DE OLIVEIRA; GOMES, 2014, p. 74). Ou seja, eles precisam saber do reconhecimento do outro, tal liberdade deve, portanto, ser identificada e reconhecida pelo outro para que ela possa ser legitimada.

É básico à teoria da liberdade honnethiana, o reconhecimento dos outros sobre essa questão, assim, define-se além de uma figura apendicular de condicionamento externo e uma dependência recíproca de existência intersubjetiva (HONNETH, 2015, p. 94). "Honneth adota uma compreensão muito ampla de reconhecimento e enquadra na categoria demandas e 
reinvindicações que vão muito além das políticas de identidade, vocalizadas pelos movimentos sociais contemporâneos" (SARMENTO, 2016, p. 248).

É uma leitura arriscada da teoria de Axel Honneth que se baseia na relação intersubjetiva de (obviamente) pessoas vivas, mas quando se integra essa discussão a ideia da memória e lembrança, porque não este reconhecimento seja possível legitimar ainda o reconhecido, quando o reconhecedor estiver morto. Não é a base do trabalho discutir ou compreender o tema na teoria do filósofo alemão, mas aqui se traz a discussão para demonstrar como o direito à memória e lembrança são subjetivos a ponto de dependerem de uma relação entre os sujeitos, pois o autor também se debruça a estudar as relações familiares.

Nessa toada de relações entre os sujeitos vivos e as lembranças, pode-se destacar também o luto, necessidade pessoal de alguns muito estudado pelo comportamento humano. É analisado nas relações entre os familiares dos mortos, e a necessidade do luto para consolar a perda, que

muitos parentes se preocupam com memórias e ficam ruminando fantasias, chegando, muitas vezes, a falar com o falecido como se ainda estivesse vivo. Além de se isolar dos 83 vivos, tornam mais difícil encarar a realidade da morte da pessoa. Entretanto, para alguns, esta é a única forma de aceitar a perda (KÜBLER-ROSS, 1998, p. 191).

Nessa dependência e relação entre os sujeitos, analisa-se agora um último instituto normativo a ponto de possibilitar o debate e a reflexão para o pós-leitura. É certo desde o início do trabalho que não há a pretensão de encaixar a eficácia dos direitos post mortem em apenas uma categoria, mas demonstrar o quão profícuo e próximo à natureza humana é a temática. Assim, passa-se a presenciar no trabalho um desdobramento do princípio da afetividade familiar, que se ramifica com a necessidade de proteção da dignidade da pessoa morta (DIAS, 2017 e TARTUCE, 2008).

Recorre-se à morte com eufemismos (KÜBLER-ROSS, 1998, p.11), e por isso é tão próximo o sentimento do carinho ou estima social da proximidade e do afeto.

A doutrina se divide em três principais correntes: a) a primeira argumenta que a afetividade deve ser reconhecida e pode ser classificada como um princípio jurídico; b) a segunda alega que deve ser assimilada pelo direito, mas apenas como um valor relevante; c) já a terceira corrente sustenta que a 
afetividade não deve ser valorada juridicamente (entende que o afeto é um sentimento, o que seria estranho ao direito) (CALDERÓN, 2013, p. 4).

O afeto e essa abertura aos sentimentos por parte do estudo jurídico é necessário para a compreensão do direito civil, uma vez que ele demanda as relações intersubjetivas a sua análise e compreensão dos fatos ocorridos. Portanto, diante dessa leitura da afetividade para o direito trazida acima, ressalta-se que é necessário reconhecer estes valores para compreender tanto a personalidade, a memória, a relação familiar, ou o próprio sujeito de direitos, tão complexo e necessitado de reconhecer suas origens e buscas da identidade. Para entender uma dignidade post mortem é necessário que o direito se abra ao campo mais humanístico, muito custoso a um panorama positivista e legalista que é ordenamento.

\section{A efetividade da tutela nos tribunais: ao direito importa os mortos?}

$\mathrm{O}$ direito se destina às pessoas vivas. $\mathrm{E}$ isto é regra dos primeiranistas de qualquer faculdade de direito: a personalidade, a possibilidade de ser encarado como um sujeito de direitos, se inicia com a respiração extrauterina, no nascimento com vida, e tem o fim de sua existência com a morte (artigo $6^{\circ}, \mathrm{CC}$ ). Aos vivos, o direito se faz presente, mas como já foi visto e muitos autores discutem sobre essa relação há as controvérsias, e as questões jurídicodoutrinárias que indicam ressalvas à adoção dessas regras para a eficácia além-vida. $\mathrm{O}$ presente artigo não possui o condão de criticar ou ajuizar qualquer tipo de teoria, concordando ou não, mas a discussão proposta aqui é se o direito, no sistema em que ele se apresenta hoje, possui formas de assegurar uma tutela jurídica a um sujeito morto.

Quando se analisa os artigos da eficácia post mortem dos direitos da personalidade do Código Civil de 2002, tem-se a certa noção que o direito da personalidade é vinculado ao seu titular, mas a defesa dele, a honra dele, a dignidade da pessoa não viva, pode ser objeto de debate jurídico, mas este realizada por pessoas vivas. O texto do parágrafo único, do artigo 12, concede ao cônjuge sobrevivente ou algum parente a exigência de que "cesse a ameaça, ou a lesão, a direito da personalidade, e reclamação perdas e danos, sem prejuízo de outras sanções previstas em lei”. A dignidade exposta é da pessoa morta, mas o direito de agir é do vivo. A discussão e o debate que podem surgir é a subjetividade desses elementos da vida de cada um coincide com a da família? 
Pode-se dizer que pessoas da família mantêm uma carga valorativa e decisões de cunho social, mas isto está longe de ser uma regra, ou debandar uma generalidade institucionalizada. O caráter do subjetivo daquilo que é ofendido pode ocasionar diversos valores diferentes entre várias pessoas, e como prolongar um entrave judicial de uma discussão sobre um elemento da vida de alguém sem saber quais eram os limites que aquela pessoa estipularia, pois ela está morta? É necessário buscar meios e caminhos também que possibilitem o uso da emoção, como o viés da arte. Pois, o direito é mais duro nessa seara e debanda com o princípio de agir de quem de fato está vivo e comandando a ação. Então, a dignidade da pessoa morta, não é mais uma questão de coerência ou relevância para a aplicação do direito.

Excepcionalmente, há proteção post-mortem de alguns direitos da personalidade previstos no ordenamento jurídico pátrio, a saber: direito ao nome, à intimidade, à vida privada, à honra, como o texto do artigo 20 no Código Civil diz expressamente. Na Ação Direta de Inconstitucionalidade $\mathrm{n}^{\circ} 4815$, decidido em plenário em 2015, publicado o acórdão em 2016, entendeu-se que o Estado não pode interferir em produções bibliográficas com o intuito de transparecer uma censura prévia de algo. Ou seja, a história das pessoas falecidas, por meio dessa decisão do STF, da relatora a Ministra Carmem Lúcia, não há necessidade de autorização das pessoas presentes numa obra de cunho bibliográfico, sejam vivas ou falecidas $^{12}$.

A decisão, contudo, demonstra que não ficam sem respaldo as possíveis indenizações e direito de resposta. Aqui, se demonstra nesse entendimento que a tutela da personalidade em compensação com as liberdades constitucionais não é priorizada. $\mathrm{Na}$ decisão, ainda se diz: "biografia é história. A vida não se desenvolve apenas a partir da soleira da porta de casa". Ou seja, a vida e a personalidade de um indivíduo pode ajudar a contar a história de um outro. Assim, a pessoa morta e a história que ela viveu faz parte da sociedade, não tendo a possibilidade de alguém a impedir de ser contada.

Ainda, outro caso sobre direito de pessoas falecidas, vem a discussão sobre a discussão de órgãos depois da morte. Se o indivíduo deixar expressamente a sua decisão em vida, ela será

12 "Ação direta julgada procedente para dar interpretação conforme à Constituição aos arts. 20 e 21 do Código Civil, sem redução de texto, para, em consonância com os direitos fundamentais à liberdade de pensamento e de sua expressão, de criação artística, produção científica, declarar inexigível autorização de pessoa biografada relativamente a obras biográficas literárias ou audiovisuais, sendo também desnecessária autorização de pessoas retratadas como coadjuvantes (ou de seus familiares, em caso de pessoas falecidas ou ausentes)." ADIN 4815/STF. 
válida. Contudo, se ele não deixar nenhum documento expresso apenas consentido no seio familiar de qual é a sua vontade, esta terá que ser convalidada pela família, não tendo maiores reflexos jurídicos - a não ser éticos e morais - de uma decisão contrária do morto, se essa não tiver registrada.

O enunciado 227, da IV Jornada de Direito Civil afirma:

O art. 14 do Código Civil, ao afirmar a validade da disposição gratuita do próprio corpo, com objetivo científico ou altruístico, para depois da morte, determinou que a manifestação expressa do doador de órgãos em vida prevalece sobre a vontade dos familiares, portanto, a aplicação do art. $4^{\circ}$ da Lei n. 9.434/97 ficou restrita à hipótese de silêncio do potencial doador.

Há relatos de que a decisão denegatória da família sobre a doação de órgãos é decidida pela emoção do momento e de convicções pessoais, muito embora o assunto tenha sido externado de outra maneira pelo sujeito morto, ou mesmo nunca tendo comentado, e assim resta a dúvida de sua real vontade. É, portanto, muito dificultoso falar sobre uma dignidade post mortem, pois o direito é um sistema destinado a pessoas vivas, e se morrerem o direito sucessório e patrimonial o tratam como objetos, e não mais como sujeitos. Assim reconhecer como um direito da personalidade, ou uma decorrência do afeto, da estima, da memória ou da liberdade, é ainda muito distante do ordenamento jurídico brasileiro.

Diversos autores trazem questões sobre a tutela da personalidade (IGLESIAS, 2003; TEPEDINO, 1999). Todas essas tutelas e análises poderiam ser trazidas aqui com a ideia de que perpassa a discussão levantada aqui e tentar subjetivar as discussões jurídicas para o além do cartesiano imposto. Reconhecer tal valor demonstra uma carga interpretativa do norteamento ao ordenamento que o respeito ao indivíduo se demonstra entre seus pares, a memória, o afeto para além da vida também indicam os sujeitos e pessoas que cada um na população é e o direito deve se atentar para tanto. Assim, repete-se a responsabilidade do Estado em reconhecer a personalidade do indivíduo como uma demonstração de sua própria dignidade.

Para finalizar, então, traz-se mais um conceito de dignidade:

A dignidade da pessoa humana não consiste apenas no fato de ser ela, diferente das coisas, um ser considerado e tratado em si mesmo [...]. Ela resulta também do fato de que, pela sua vontade racional, só a pessoa vive 
em condição de autonomia, isto é, como ser capaz de guiar-se pelas leis que ele próprio edita. [...] O homem é o único ser no mundo dotado de vontade, isto é, da capacidade de agir livremente, sem ser conduzido pela imutabilidade do instinto. [...] é sobre o fundamento último da liberdade que se assenta todo fundamento axiológico, isto é, o mundo das preferências valorativas, bem como toda ética de modo geral, ou seja, o mundo das normas [...] (COMPARATO, 2007, p. 23-25).

O trecho é importante para arrematar o posicionamento do artigo de debate ao plano paradigmático que o direito se propõe, e dentro de discussões de direito e arte, é possível abstrair conceitos. Defender uma dignidade post mortem, ou até mesmo - para os positivistas não reclamarem -, os direitos da personalidade com eficácia post mortem é preciso de uma compreensão do indivíduo como um todo, como um ser que possui identidade, que demonstra seu afeto, que morre e quer ser lembrado ou suas decisões respeitadas. Assim, o direito não se importa com os mortos, mas deveria possuir um cenário de maior respeito às suas decisões e encontrar nos debates mais subjetivos, o elo da vida e da morte, ambos importantes cenários jurídicos.

\section{CONCLUSÕES}

Ao direito, portanto, parece risível a dignidade post mortem com o sujeito morto como titular de seus direitos, pois as suas positivações ou preocupações se dão perante às decisões tomadas em vida, ou a tutela de um direito que já não é mais o da personalidade signatário da pessoa viva. Mesmo assim, a discussão sobre a questão ética do respeito e da memória pelo ente familiar morto que este ártico elucida e o filme ilustra tão bem integra uma proposta de enxergar o direito com um caráter mais humanista, e respeitador aos preceitos fundamentais e humanísticos do convívio da sociedade. Uma pessoa morta não é apenas os direitos patrimoniais que do seu falecimento depreenderam. E sim, todo a compreensão da sua dignidade que continua como uma unidade na lembrança e memória das pessoas que continuam vivas ou na perpetuação de sua atividade entre seus pares. Ao entender a dignidade como uma unicidade e uma forma de compreensão da identidade do indivíduo, ela deve continuar sendo respeitada para além morte.

Como o direito é feito e programado para pessoas vivas, dotadas da personalidade que iniciam com o nascimento com vida e finalizam com a morte, e assim não podem mais agir como sujeitos de direitos, a dignidade post mortem não apresenta uma natureza jurídica 
específica ou uma tutela própria ou independente de uma condição de agir de alguém vivo. Assim, as ações para após vida deixadas registrada em vida são uma saída efetiva à esse respeito da dignidade ou ainda uma noção por parte da família da continuidade refletida da personalidade, da dignidade e do afeto do ente morto. Parece utópico uma conclusão como essa, ou a necessidade do direito promover uma concepção ética da família pela memória e lembrança de seus entes, mas o filme "Viva! A vida é uma festa" demonstra muito bem essa necessidade. Com o recurso da fantasia e permitido pela subjetividade da arte e um roteiro baseado nas noções mágicas e espirituais da morte, a dignidade em vida tem seus reflexos para aqueles que continuam vivos e para os mortos na certeza que sua identidade está preservada. Se a vida é uma festa, ao direito importa fazer com que a memória dos mortos também seja.

\section{REFERÊNCIAS BIBLIOGRÁFICAS}

ALMEIDA NETO, João Beccon de et al. O valor social do cadáver humano: personalidade, pesquisa científica, doação de órgãos e corpos. Direito \& Justiça, v. 34, n. 1, 2008.

ANDRADE, Fábio Siebeneichler de. A tutela dos direitos da personalidade no direito brasileiro em perspectiva atual. Revista de Derecho Privado, n. 24, p. 81-111, 2013.

BARROSO, Luís Roberto. A dignidade da pessoa humana no Direito Constitucional contemporâneo: a construção de um conceito jurídico à luz da jurisprudência mundial. $1^{\text {a }}$ reimpressão. Belo Horizonte: Editora Fórum. 2013.

BITTAR, Carlos Alberto. Os direitos da personalidade. 8. Ed. São Paulo: Saraiva, 2015.

CALDERÓn, Ricardo Lucas. Princípio da afetividade no direito de família. Rio de Janeiro: Renovar, 2013.

CARNELLUTTI, Francesco. "Diritto alla vita privata (contributo alla vita privata)", in Rivista trimestrale di diritto pubblico, 1955, p. 3

CATTONI DE OLIVEIRA, Marcelo Andrade e GOMES, David. Constitucionalismo e Dilemas da Justiça. Belo Horizonte: Ed. Initia Via, 2014, p. 66 a 85.

CHARLES, Sébastien; LIPOVETSKY, Gilles. Os tempos hipermodernos. São Paulo: Barcarolla, 2004. 
COCENTINO, Jamille Mamed Bomfim; VIANA, Terezinha de Camargo. A velhice e a morte: reflexões sobre o processo de luto. Revista Brasileira de Geriatria e Gerontologia, v. 14, n. 3, p. 591-599, 2011.

COMPARATO, Konder Fábio. A afirmação histórica dos Direitos Humanos. 5. Ed. São Paulo: Saraiva, 2007.

DE CUPIS, Adriano. I diritti della personalità, Milano, Giuffrè, 1982, p. 13.

DIAS, Maria Berenice. Manual de direito das famílias. Editora Revista dos Tribunais, 2017.

FRANÇA, Limongi Rubens. Instituiçõos de direito civil. 3.a. ed. atual. São Paulo: Saraiva, 1994, p. 1033.

- Direitos da Personalidade. Coordenadas Fundamentais. São Paulo: Revista dos Tribunais, 1983. n 567.

HONNETH, Axel. O direito da liberdade. São Paulo: Martins Fontes, 2015.

KUBLER-ROSS Elizabeth. Sobre a morte e o morrer: o que os doentes terminais têm para ensinar a médicos, enfermeiras, religiosos e a seus próprios parentes. São Paulo: Martins Fontes, 1998

PAOLI, Maria Célia. Memória, história e cidadania: o direito ao passado. In. O direito à memória: patrimônio histórico e cidadania. São Paulo: DPH, 1992, p. 25-28.

PONTES DE MIRANDA. Tratado de Direito Privado. Tomo 7. Campinas: Bookseller, 2000.

RIZZATTO NUNES, Luiz Antônio. O Principio Constitucional da Dignidade da Pessoa Humana. São Paulo: Saraiva, 2002.

SARLET, Ingo Wolfgang. As dimensões da dignidade da pessoa humana: construindo uma compreensão jurídico-constitucional necessária e possível. Revista brasileira de direito constitucional, v. 9, n. 1, p. 361-388, 2007.

Dignidade da pessoa humana e direitos fundamentais na Constituição

Federal de 1988. 5. ed. Porto Alegre: Livraria do Advogado, 2012.

SARMENTO, Daniel. Dignidade da pessoa humana: conteúdo, trajetórias e metodologia. 2. Ed. Belo Horizonte: Fórum, 2016. 
SAVATER, Fernando. A morte, para começar. In: SAVATER, Fernando. As perguntas da vida. Martins Fontes. São Paulo, 2011 p. 13- 26.

SILVA, José Afonso da. A dignidade da pessoa humana com valor supremo da democracia. Revista de direito administrativo, v. 212, p. 89-94, 1998.

SOUZA, Jessé. A tolice da inteligência brasileira: ou como o país se deixa manipular pela elite. São Paulo: LeYa, 2015.

TARTUCE, Flávio. Novos princípios do direito de família brasileiro. In. Manual de direito das famílias e das sucessões. Coordenado por Ana Carolina Brochado Teixeira e Gustavo Pereira Leite Ribeiro. Belo Horizonte: Del Rey Editora, 2008.

TEPEDINO, Gustavo. A tutela da personalidade no ordenamento civil-constitucional brasileiro. Temas de direito civil, v. 3, p. 25, 1999.

TORRES, Wilma da Costa. A bioética e a psicologia da saúde: reflexões sobre questões de vida e morte. Psicologia: reflexão e crítica, v. 16, n. 3, p. 475-482, 2003.

VASCONCELOS, Pedro Pais de. Direito de personalidade. Coimbra: Almedina, 2014. 